\title{
A Study Regarding Awareness among the University Students about the Disease Beta Thalassemia
}

\author{
Manoj Kumar'*, Somisetti Mukunda valli1, Vijay Lakshmi Sharma1, N \\ aveen Kishan Goel ${ }^{2}$ and Alka Sehgal ${ }^{3}$ \\ ${ }^{1}$ Centre for Public Health, Panjab University, India \\ 2Department of Community Medicine, GMCH, India \\ ${ }^{3}$ Department of Gynaecologist, GMCH, India
}

Research Article

Volume 3 Issue 2

Received Date: June 06, 2019

Published Date: July 01, 2019

DOI: $10.23880 /$ phoa- 16000137

*Corresponding author: Manoj Kumar, Assistant Professor, Centre for Public Health, Panjab University, Chandigarh, India, Email: mkcph@pu.ac.in

\section{Abstract}

Background: Thalassemia is an inherited blood disorder in which the body is unable to make adequate haemoglobin. Haemoglobin is present in the red cells. Normally red cells survive for 120 days but in Thalassemia red cell survival is reduced. Most children with thalassaemia are born in low-income countries. Worldwide, transfusion is available for a small fraction of those who need it, and most transfused patients will die from iron overload unless an available and potentially inexpensive oral iron chelator is licensed more widely.

Methods: A Cross sectional study was conducted among the university students from January 2011 to May 2011. Simple random sampling was done. There are 66 departments in Panjab University, Chandigarh, 14 and 25 sector campuses. From each department of the University residential campuses 6 students were selected randomly. Hence making 400 students approximately from 66 departments.

Results: Responses for knowledge about anemia, thalassemia, beta thalassemia among study subjects in preliminary questionnaire survey had shown that in the pre information questionnaire around $73.6 \%$ of the students enrolled in the study had no knowledge about anemia, thalassemia, beta thalassemia and its types and significance.

Conclusion: It can be concluded that awareness among sciences students were more (28.6\%) about the disease than the students of other faculties of study.

Keywords: Anemia; Thalassemia; Beta thalassemia

\section{Introduction}

Thalassemia is a blood disorder passed down through families in which the body is unable to make adequate haemoglobin. This results in anaemia. Anaemia is a disorder where there is less than normal quantity of haemoglobin in blood leading to decrease in oxygen carrying capacity of blood.

Beta Thalassemia is also called as Cooley's anemia. It occurs when a gene or genes related to the beta globin protein of haemoglobin are missing or changed 
(mutated). It is estimated that 1 lakh babies a year in India alone are born with severe form of Beta Thalassemia (Thalassemia major) [1].

Children inherit one gene from either parent. If both the genes carry the disease, baby born is not able to form haemoglobin and become sick in childhood itself. The child is blood transfusion dependent and still lives for some years only. On the other hand, if the child inherits disease from one parent and normal gene from the other parent, then the child lives a near normal life and is called a thalassemia trait or thalassemia minor [2].

Symptoms of thalassemia can be classified as:

Mild: Some people are "silent carriers" of beta thalassemia (Thalassemia minor) and do not have any symptoms. People who are silent carriers have beta thalassemia trait. They often have mild anaemia, which is only diagnosed through a blood test $[2,3]$.

Moderate: Individuals with beta thalassemia intermedia may have clinical severity of the disease somewhere between the mild and the severe symptoms of $\beta$ thalassemia.

Severe: These occur in individuals with Thalassemia major. Possible symptoms include: Fatigue and weakness, Pale skin or jaundice (yellowing of the skin), Bone deformities in the face, Protruding abdomen with enlarged spleen and liver, Dark urine, Poor growth and Poor appetite.

\section{Diagnosis}

The diagnosis of thalassemia trait and thalassemia major is simple and includes microscopic examination of the blood. The complete haemogram, nestroft test is followed by confirmation with more specialized tests.

\section{Treatment}

The primary treatment is regular blood transfusions, usually every four weeks. In addition to the blood transfusions, doctors recommend injections of Desferal to help the body flush out the extra iron created by the new blood [4]. (chelation therapy) Additionally, splenectomy (removal of the spleen), bone marrow transplants are being researched as possible treatments for thalassemia.

However the most important issue to remember would be not to marry a beta thalassemia trait. If one fails to do and marries a $\beta$ thalassemia trait then the couple is likely to have sick child dependent on blood transfusion. Such a child have emotional, physical, financial, psychological and social burden on the family as well as society. However, if one is aware of this good genetic counselling practice or advice and taking tests early can avoid this [5].

\section{Unaffected Carrier Father Unaffected Carrier Mother}

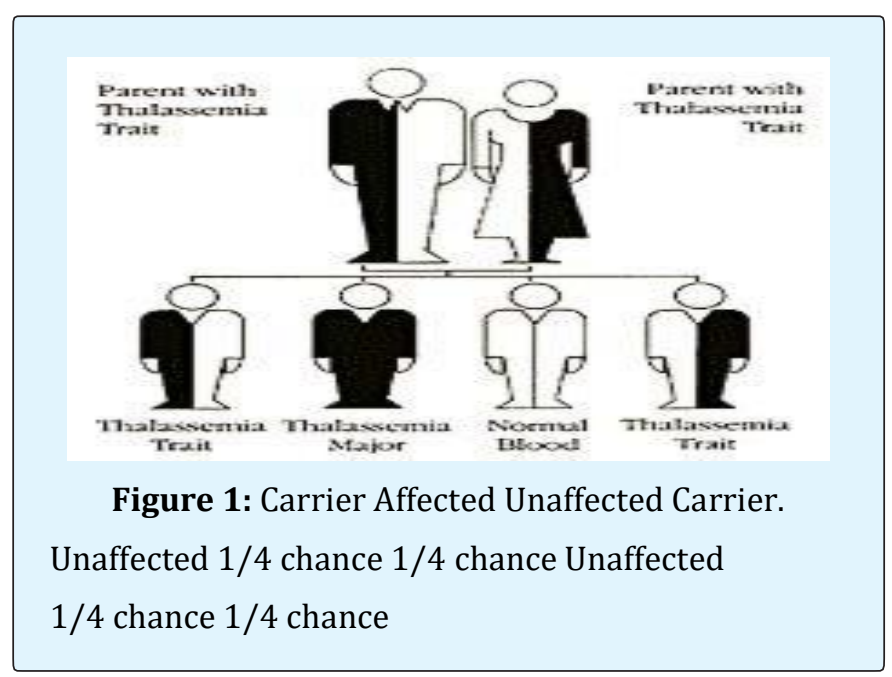

The main purpose of the present study is to make an attempt to prevent the birth of thalassemic children. Moreover, the dearth in research on awareness of thalassemia in Chandigarh has led to this study. In the present study we aim to assess the awareness about Beta Thalassemia among the students of a university and creation of awareness among them and the impact of awareness thereof. The reason for focussing on the students either married or unmarried is for encouraging caution before partner selection and before pregnancy; pregnant women are targeted to prevent the birth of Thalassemia major children by terminating the pregnancy within the first trimester. The prevention of even a single Thalassemia major child due to creation of awareness would prove success of this study $[5,6]$.

\section{Methodology}

Following research methodology was adopted which refers to the set of methods or procedures, or to the rationale and the philosophical assumptions that underlie this particular study. Its sub sections are the following:

\section{Study Design}

Cross sectional study design was chosen.

\section{Study Area}

The Panjab University was chosen as the study area. 


\section{Sample size}

Based on convenience and resources available sample size of 400 students was taken.

\section{Sampling}

Simple random sampling was done. There are 66 departments in Panjab University, Chandigarh, 14 and 25 sector campuses. The total number of students enrolled in the various residential departments of the University campuses in the year 2010- 2011 is 11642 . From each department of the University residential campuses 6 students were selected randomly. Hence making 400 students approximately from 66 departments. Random table method was used to select students from the attendance registers of different departments.

\section{Study Period}

The study was undertaken for a period of 5 months from January 2011 to May 2011.

\section{Data Collection}

The study consisted of its 3 basic pillars; Pre-test, health education and Post-test. Upon enrolment in the study, each student filled out a pre-designed structured data collection sheet.

Data was collected on a pre-design, pre-tested questionnaire. The pretest questionnaire was provided to find the student's awareness about the disease Beta Thalassemia, information sheet about Beta thalassemia was provided to each student enrolled in the study to improve their knowledge about Beta thalassemia. The information sheet consisted of basic information about the disease which the respondent had to read after the pre information questionnaire is answered. The posttest included same questions inquired in Pre-test. The questionnaire comprises of 20 questions. 8 questions in the pre-test and 12 in the posttest out which 4 questions were based on the respondent's feedback about the awareness created. The Feedback of the awareness includes the queries of the respondent regarding the information provided or any further information required by the respondent, the suggestions if any of the respondents to improvise the awareness method and the willingness to get their blood tested for Thalassemia trait and spread the information provided to others $[6,7]$. It took around 15-20 minutes for the each respondent to complete filling the questionnaire.

\section{Data Analysis}

After collecting the required information from the subject, the responses were coded numerically and the responses for each open ended question in the pre and posttests was given grades basing on a prepared scale taken as a standard.

Grades for Knowledge: The grade for each answer was given in 6 categories.

- No knowledge

- Fair knowledge

- Good knowledge

- Very good knowledge

- Excellent knowledge

- Near Complete

"Do not know" answers and wrong answers were taken in 'No knowledge' category. The answers where the respondents gave the physical symptoms of the disease were given 'Fair' grade. More grades were given to responses where the genetic aspect or pathology of disease was mentioned. In questions where significance of minor or major was asked high grades for knowledge was given to responses mentioning the impacts of such state (minor or major thalassemia).

\section{Statistical Analysis}

The collected data were reviewed, coded, verified and statistically analyzed using computer program SPSS version 16. Non parametric statistical tests were used which include Wilcoxon Signed Ranks to compare proportions with different knowledge scores before and after the program and Kruskal Wallis test for the comparison of knowledge among different streams of study in pretest and the same in the posttest. The frequencies and cross tabs were built. Statistical significance was set at $\mathrm{p}<0.05$.

\section{Results}

Out of estimated sample size of 400 students from the 66 departments in the University campus, 378 students (63 departments) were covered in the study. Demographic profile of awareness regarding beta thalassemia and awareness after the education program on beta thalassemia was collected and analysed using Microsoft excel and SPSS 16.0 software [8,9]. 
Most of the students enrolled in the study were in the age group of 21and 22yrs. The number of female students who participated in the study was 200 and the number of male students was 178 .

The 63 teaching and research departments of Panjab University were clubbed into 9 streams of study. Table 1 shows that the number of students enrolled in the present study was highest in the Faculty of Arts as it constitutes highest number of departments in the University. Lowest number was in Faculty of Laws, Dental and Pharmaceutical sciences. To find the impact of awareness crosstabs were used for both close ended and open ended part of each question regarding knowledge assessment in pre and post information questionnaires [10].

Table 1 shows that the number of students enrolled in the present study was highest in the Faculty of Arts as it constitutes highest number of departments in the University.

Lowest number was in Faculty of Laws, Dental and Pharmaceutical sciences.

To find the impact of awareness crosstabs were used for both close ended and open ended part of each question regarding knowledge assessment in pre and post information questionnaires.

\begin{tabular}{|c|c|c|}
\hline Stream of Study & $\begin{array}{c}\text { Number of } \\
\text { Departments } \\
(\mathbf{n = 6 3 )}\end{array}$ & $\begin{array}{c}\text { No. of study subjects } \\
(\mathbf{n = 3 7 8 )}(\mathbf{6})\end{array}$ \\
\hline Arts & 16 & $102(27)$ \\
\hline $\begin{array}{c}\text { Management \& } \\
\text { Commerce }\end{array}$ & 3 & $18(4.8)$ \\
\hline Design \& Fine Arts & 3 & $18(4.8)$ \\
\hline Education & 7 & $42(11.1)$ \\
\hline $\begin{array}{c}\text { Engineering \& } \\
\text { Tech. }\end{array}$ & 4 & $24(6.3)$ \\
\hline Languages & 10 & $54(14.3)$ \\
\hline Law & 2 & $12(3.2)$ \\
\hline $\begin{array}{c}\text { Dental and } \\
\text { pharmacy }\end{array}$ & 2 & $12(3.2)$ \\
\hline $\begin{array}{c}\text { Sciences (Pure \& } \\
\text { Applied) }\end{array}$ & 16 & $96(25.4)$ \\
\hline Total & 63 & $378(100)$ \\
\hline
\end{tabular}

Table1: Stream wise distribution of the study subjects.

Responses for presence of awareness about anemia among study subjects were that $70 \%$ students said they knew about anemia in the pretest. in the posttest 93\% students said they knew about anemia.
Responses for presence of awareness about thalassemia among study subjects had shown that $52 \%$ students enrolled in study said they heard about thalassemia in the pretest. Whereas in the posttest $92 \%$ students said they knew about thalassemia.

Responses for presence of awareness about beta thalassemia among study subjects were that only $20 \%$ students heard about beta thalassemia as a disease of children in the pretest. In the posttest $88 \%$ students said they knew about beta thalassemia.

Responses for presence of awareness about major and minor varieties of beta thalassemia among study subjects were that $14 \%$ students said they knew about the major and minor types of Beta Thalassemia in the pretest. In posttest $86 \%$ students said they knew about major and minor varieties of Beta Thalassemia.

Responses for presence of awareness about thalassemia major among study subjects were that $12 \%$ students said they knew about Thalassemia major in the pretest. Whereas in the posttest $86 \%$ students said they knew about Thalassemia major.

Responses for presence of awareness about thalassemia minor among study subjects were that $11 \%$ students said they knew about Thalassemia minor in the pretest. Whereas $86 \%$ students said they knew about Thalassemia minor in the posttest.

Responses for presence of awareness about significance of marrying thalassemia minor to thalassemia minor among study subjects were that $15 \%$ students said they knew the significance of a Thalassemia minor marrying Thalassemia minor in the pretest. In the posttest $83 \%$ students said they knew about the significance of marrying of two thalassemia minors.

Responses for necessity regarding taking thalassemia test before marriage were that in the pretest 36\% students think thalassemia test is necessary before marriage. Whereas in the posttest $90 \%$ students think thalassemia test is necessary before marriage.

Responses for knowledge about anemia among study subjects (Open ended questions) had shown that 30\% students had no knowledge about anemia in the pretest. However, in the posttest only $3 \%$ students had no knowledge about anemia. 
$33 \%$ students had very good knowledge about anemia in the pretest. Whereas in the posttest $63 \%$ students had very good knowledge about anemia.

By applying Wilcoxon signed rank test to the above grades of pre and posttests for knowledge about anemia the $p$ value obtained was .000 . Statistical significance was set at $p<0.05$. Hence the test was highly significant. The education provided after pretest improved the knowledge significantly.

Responses for knowledge about thalassemia among study subjects had shown that $62 \%$ students had no knowledge about thalassemia in the pretest. However, in the posttest only $5 \%$ students had no knowledge about thalassemia.

In the pretest only $0.5 \%$ students had excellent about thalassemia. Whereas in the posttest $31 \%$ students had excellent knowledge about thalassemia.

By applying Wilcoxon signed rank test to the above grades of pre and posttests for knowledge about thalassemia the $\mathrm{p}$ value obtained was .000 . Hence the difference was highly significant. The education provided after pretest improved the knowledge amongst students significantly.

Responses for knowledge about beta thalassemia among study subjects were that $80 \%$ students had no knowledge about beta thalassemia in the pretest. However, in the posttest only $9 \%$ students had no knowledge about beta thalassemia. In the pretest only $7 \%$ of the students had very good knowledge about beta thalassemia. Whereas in the posttest 35\% students had very good knowledge about beta thalassemia.

By applying Wilcoxon signed rank test to the above grades of pre and posttests for knowledge about beta thalassemia the $\mathrm{p}$ value obtained was .000 . Hence the difference was highly significant. The education provided after pretest improved the knowledge amongst students significantly.

Responses for knowledge about thalassemia major among study subjects were that $87 \%$ students had no knowledge about beta thalassemia major in the pretest. However, in the posttest only $11 \%$ students had no knowledge about beta thalassemia major. In the pretest only $4 \%$ of the students had good knowledge about beta thalassemia major. Whereas in the posttest $31 \%$ students had good knowledge about beta thalassemia major.
By applying Wilcoxon signed rank test to the above grades of pre and posttests for knowledge about beta thalassemia major the $\mathrm{p}$ value obtained was .000 . Hence the difference was highly significant. The education provided after pretest improved the knowledge amongst students significantly.

Responses for knowledge about thalassemia minor among study subjects were that $90 \%$ students had no knowledge about beta thalassemia minor in the pretest. However, in the posttest only $10 \%$ students had no knowledge about beta thalassemia minor. In the pretest only $3 \%$ of the students had good knowledge about beta thalassemia minor. Whereas in the posttest $34 \%$ students had good knowledge about beta thalassemia minor. By applying Wilcoxon signed rank test to the above grades of pre and posttests for beta thalassemia minor the $p$ value obtained was 0.000 . Hence the difference was highly significant. The education provided after pretest improved the knowledge amongst students significantly.

Responses knowledge about significance of marrying beta thalassemia minor to beta thalassemia minor among study subjects had shown that $85 \%$ students had no knowledge about beta thalassemia minor in the pretest. However, in the posttest only $14 \%$ students had no knowledge about beta thalassemia minor. In the pretest only $4 \%$ of the students had good knowledge about beta thalassemia minor. Whereas in the posttest $32 \%$ students had good knowledge about significance of marrying beta thalassemia minor to beta thalassemia minor.

Wilcoxon signed rank test to the above grades of pre and posttests for knowledge about significance of thalassemia minor marrying thalassemia minor shows the $\mathrm{p}$ value obtained as 0.000 . Hence the difference was highly significant. The education provided after pretest improved the knowledge amongst students significantly.

Responses for knowledge about anemia, thalassemia, beta thalassemia among study subjects in pre \& post questionnaire survey had shown that in the pre information questionnaire around $73.6 \%$ of the students enrolled in the study had no knowledge about anemia, thalassemia, beta thalassemia and its types and significance. However, in the post questionnaire survey around $8.8 \%$ of the students had no knowledge about the same questions as in the pretest. Hence the significant difference in the knowledge of the students across pre and post information tests indicates the positive impact of the awareness created among the students of Panjab University. 


\section{Discussion}

Only few sporadic studies have been carried out in some communities in India. The exact magnitude of the problem in India is still not known. Only hospital-based data are available, which cannot be regarded as representative of the community or population [11].

This study has contributed to the cause of making people aware about Beta Thalassemia by creating awareness among the students of Panjab University. The current study is the first educational program conducted among university students in Chandigarh. The majority of participants have never been tested for thalassemia, the reasons being unawareness or if they were aware, they simply did not consider doing the test. It is a fact that unawareness causes people to overlook screening tests for diseases and this should not happen with a disorder that has a carrier frequency of $3-15 \%$ (in North India) [12-14]. However after the education about Thalassemia was provided most were positive about the benefits of testing and indicated their willingness to be tested. Thus, promotion of screening among the students is likely to receive a favourable response. The higher knowledge score among those enrolled in Dental and pharmaceutical science and applied science faculties may reflect understanding of genetic and infectious diseases acquired during their studies. This indicates the importance of introducing such information in secondary schools and university curricula.

The present study is an improvement over a study carried out by Parakhiya Vasant at Indian Red Cross Society, Ahemadabad in which 50 college students of Gandhinagar were included to study awareness and to create awareness about the Thalassemia among them [15]. This particular study used a questionnaire lacking open ended questions.

A Study conducted by John Mitchell in Montreal among 14,844 students of High schools which included education, screening, and counselling of the students for Beta thalassemia diseases was continued for 20 years of time [16,17]. The Study included dissemination of knowledge to the students about Thalassemia but did not aim to assess the knowledge of students about the disease. The present study, apart from finding awareness among the students and creating awareness, purports to get the feedback of the awareness created among them.

The study highlights the urgent need for making the people aware of lethal disease. Health education is an important component of the preventive genetic programmes [18]. The WHO has advocated that focus be placed on public education, detection of genetic risks in the community and premarital genetic counselling. Education not only increases awareness, it can also help a thalassemic sufferer to be an active member of a society. Educated parents also play an important role in advocacy. A survey conducted in England among population of South Asian descent in 1995 found that only 25\% were aware of thalassaemia. After a 3-year awareness campaign via various platforms, the awareness increased to $60 \%$ in 2000 . Similarly the percentage of reported blood screening increased from $4 \%$ to $10 \%$ after this campaign [19]. This shows that awareness campaigns are effective in enabling the community or population to make informed choices.

In light of our results, there is certainly a need for more information and education about the disease Beta thalassemia. The lack of awareness among the participants is a cause of concern. The problem could be the tip of an iceberg, indicating the lack of awareness among the Indian population as a whole despite the fact that thousands of children are born with Thalassaemia major every year in this country $[20,21]$.

\section{Conclusion}

The results of the study revealed that knowledge of students about the disease was low before providing the educational message. About $80 \%$ of the students enrolled in the study never heard of Beta Thalassemia as a disease of children. The students of Dental and Pharmaceutical sciences were more aware about the disease than the students of other faculties of study. Among the students who heard about Beta thalassemia (in the pretest) only $9 \%$ of students knew the significance of marrying thalassemia minor to minor. The strikingly low level of awareness about the disease amongst the sample of Panjab University students highlights the urgency of implementing effective public educational programs to increase publicity to stimulate concern and enhance access to thalassemia screening, patient education, and school-based promotion and screening programs. In the posttest the response for the same questions was improved to great extent. After awareness, $78 \%$ of the students enrolled in the study were willing to go for the thalassemia test. The educational program markedly improved knowledge of participants about Beta Thalassemia, $79 \%$ of the students were interested to take the thalassemia test during the post information test. Hence the impact of awareness created amongst the students participated in the study was significant. 


\section{References}

1. Weatherall D, Clegg JB (1996) Thalassemia is a global public health problem. Nat Med 2: 847-849.

2. Sengupta M (2008) Thalassemia among the tribal communities of India. The Internet Journal of Biological Anthropology 1(2): 1-9.

3. Asha shah (2004) Thalassemia Syndromes. Practitioners Section. Indian J Med Sci 58(10): 445449.

4. Das SK, De M, Bhattacharya DK, Talukder G (1997) The occurrence of thalassemia mutation, its interaction with haemoglobin $\mathrm{E}$ in Eastern India. Int J Hematol 66(1): 31-34.

5. Kukreja A, Khan A, Xian L, Razley A, Rahim Z (2009) Awareness of Thalassaemia among Rural Folks in Penang, Malaysia. The Internet Journal of Health 12(1): 1-8.

6. Rahman MJ, Rahman MH (2003) Prevention \& control strategy of thalassemia in Bangladesh. The ORION Medical Journal 16: 121-122.

7. Mulchandani DV1, Fulare MB, Zodpey SP, Vasudeo ND (2008) Prevalence of some epidemiological factors of Beta Thalassemia trait in Sindhi community of Nagpur city, India. Indian Journal of Public Health 52(1): 11-15.

8. Shrenik T, Niti T, Himanshu N (2011) A Cross Sectional Study of Thalassemia In Ahmedabad City. (Hospital based). Health line 2(1): 48-51.

9. Chattopadhyay S (2006) Rakter dosh- corrupting blood: Challenges of preventing thalassemia in Bengal, India. Soc Sci \& Med 63(10): 2661-2673.

10. Colah R, Thomas M, Mayekar p (2007) Assessing the impact of screening and counselling high school children for b-thalassaemia in India. Journal of Medical Screening 14(3): 158.

11. Arif F, Fayyaz J, Hamid A (2008) Awareness among parents of children with thalassemia major. Journal of Pakistan Medical Association 58(11): 621-623.
12. Balgir RS (2000) Burden of Haemoglobinopathies in India and challenges ahead. Current Science 79: 1110.

13. Madan N, Sharma S, Sood SK, Colah R, Bhatia LH, (2010) Frequency of $\beta$-thalassemia trait and other hemoglobinopathies in northern and western India. Indian Journal of human genetics 16(1): 16-25.

14. Al-Aama JY (2010) Attitudes towards mandatory national premarital screening for hereditary hemolytic disorders. Health Policy 97(1): 32-37.

15. Parikh P, Cotton M, Boehm C, Kazazian HH Jr (1990) Ethnic distribution of thalassemia in Indian subcontinent. Lancet 336: 1006.

16. Parakhiya V (2009) A Social Project on Thalassemia Programme at Indian Red Cross Society. Ahmedabad.

17. Mitchell JJ, Capua A, Clow C, Scriver CR (1996) Twenty-Year Outcome Analysis of Genetic Screening Programs for Tay-Sachs and 3-Thalassemia Disease Carriers in High Schools. Am J Hum Genet 59(4): 793798.

18. Yagnik H (1997) Post Counselling Follow-up of Thalassemia in High Risk Communities. Indian Pediatrics 34: 1115-1118.

19. WHO (1982) Hereditary anemia: genetic basis, clinical features, diagnosis and treatment. Bull World Health Organ 60(5): 643-660.

20. Ibrahim NK, Al-Bar H, Al-Fakeeh A, Al Ahmadi J, Qadi $M$, et al. (2011) An educational program about premarital screening for unmarried female students in King Abdul-Aziz University, Jeddah. Journal of Infection and Public Health 4(1): 30-40.

21. Wong LP, George E, Tan JA (2011) A holistic approach to education programs in thalassemia for a multiethnic population: consideration of perspectives, attitudes, and perceived needs. J Comm Genet 2(2): 71-79. 